\title{
Thyroid Nodules with Preoperative Benign Cytology and BRAF V600E Mutations: the Role of Conventional Ultrasound and Shear Wave Elastography
}

\author{
Ying Zhang \\ Shanghai Tenth People's Hospital \\ Feng Lu \\ Shanghai Tenth People's Hospital \\ Yi-Feng Zhang ( $\sim 27763289 @ q q . c o m$ ) \\ Shanghai Tenth People's Hospital \\ Han-Xiang Wang \\ Shanghai Tenth People's Hospital \\ Shi Hui \\ Shanghai Tenth People's Hospital \\ Le-Hang Guo \\ Shanghai Tenth People's Hospital \\ Qing Wei \\ Shanghai Tenth People's Hospital \\ Xue-Chen Sun \\ Shanghai Tenth People's Hospital
}

Research

Keywords: ultrasound, shear wave elastography, fine needle aspiration, BRAF V600E

Posted Date: October 28th, 2020

DOI: https://doi.org/10.21203/rs.3.rs-96936/v1

License: (c) (1) This work is licensed under a Creative Commons Attribution 4.0 International License. Read Full License 


\section{Abstract}

Objectives: Ultrasound-guided fine-needle aspiration (FNA) is the most accurate and economical means for the differential diagnosis of thyroid nodules, but false negative results also existed. This study aimed to predict the false negative results of FNA, reduce the missed diagnosis and improve the current management strategy of thyroid nodules.

Methods: A total of 1232 consecutive patients with thyroid nodules who received FNA and BRAF V600E detection were adopted. All patients received both CUS (conventional ultrasound) and SWE (shear wave elastography) examinations and characteristics of these thyroid nodules were analyzed to evaluated the diagnostic performances of risk factors for malignancy.

Results: Finally, 26 nodules with benign cytology and BRAF V600E mutations were enrolled. Undefined boundary, microcalcification and E max ratio $>1.49$ were risk factors for malignancy $(P<0.05)$, and the area under the receiver operating curve (ROC) of above CUS features and elastic value were 0.817 (95\% Cl: $0.617,0.940), 0.792(95 \% \mathrm{Cl}: 0.588,0.925)$ and $0.792(95 \% \mathrm{Cl}: 0.617,0.940)$ respectively. The sensitivity, specificity, positive predictive value (PPV), negative predictive value (NPV) and accuracy were $80.0 \%, 83.3 \%, 94.1 \%, 55.6 \%$ and $80.7 \%$ for undefined boundary, $75.0 \%, 83.3 \%, 93.8 \%, 50.0 \%$ and $76.9 \%$ for microcalcification and $75.0 \%, 83.3 \%, 93.8 \%, 50.0 \%$ and $76.9 \%$ for E max ratio $>1.49$ respectively. There was no difference between benign and malignant nodules in the patient age, sex and nodule sizes $(P>0.05)$.

Conclusions: Undefined boundary, microcalcification and E max ratio > 1.49 were risk factors for malignancy in benign cytology nodules. When FNA results were benign but above characteristics could be found in the thyroid nodules with BRAF V600E mutation, further clinical decisions should be carried out to reduce the missed diagnosis.

\section{Introduction}

CUS examinations play an important role in the diagnosis of thyroid nodules based on five imaging features: solid composition, hypoechogenicity, taller-than-wide shape, irregular margins and microcalcifications[1]. Typical ultrasound characteristics were scored and aided decision-making or guided about FNA[2]. Considerate result was demonstrate on previous research that more accurate from FNA procedures performed using US guidance[3].

Fine needle aspiration (FNA) is the preferred procedure in the evaluation of thyroid nodules when sonography indicated malignancy, especially with features of most accurate and cost-effective and the diagnostic accuracy has improved when combined with FNA. However, there were approximately $25 \%$ of thyroid nodules could not be diagnosed by FNA[4]. Results of FNA benign cytology still carry the risk of malignancy up to $3 \%$ and molecular markers (BRAF, RAS, Pax8-PPARg, or galectin-3) can be used to make further guidance according to ATA guidelines[5]. Among the malignant thyroid tumors, papillary thyroid carcinomas (PTC) are the most common and the molecular marker of BRAF V600E mutations can be found in $87 \%$ PTC.

The molecular diagnosis method for PTC has been increasingly developed and especially highlighted by BRAF V600E, which is a typical and specific genetic marker that can enable effective preoperative evaluations and accurate postoperative treatment[6]. BRAF V600E has been indicated to have superiority in predicting the incidence of morality for patients with lymph node metastasis[7][8]. The combination of morphological evaluations, FNA and BRAF V600E detection significantly increased the diagnostic sensitivity from 77.3 to $86.7 \%$ of PTC over that of FNA alone[9]. A retrospective study also reported that BRAF mutations can predict malignancy in AUS/FLUS thyroid nodules and do better surgical decision[10]. However, molecular marker testing was only recommended for cytology undetermined cases up to now and benign nodules with cytology findings were not required to be tested for BRAF V600E mutations in American Thyroid Association (ATA) guidelines[5]. So far, there is no method to help find out malignant tumors in nodules with benign FNA results.

US elastography is also promising for identifying thyroid nodules suspected to be malignant during the noninvasive examination[11]. The basic imaging fundamental ability of SWE is to contrast the stiffness between benign and malignancy because the latter supposedly being harder and showed on quantitative or qualitative results. SWE was recognized as an available means for differential diagnosis of thyroid nodule with the AUC of 0.808 in maximum value[12]. In recent years, with the increasingly appearance of thyroid nodules with undetermined cytology, SWE, as a supplementary method, had performed the high sensitivity when acquiring the cut-off value of 3.3KPa and reduced repeated FNA for benign[13] Samir et al also reported that SWE can be used to identify malignancy using a lower $22 \mathrm{kPa}$ cut-off value in 35 nodules with FNA indeterminate results[14].

Our study retrospectively analyzed the CUS and SWE characteristics of those nodules with benign cytology and BRAF V600E mutation, aiming to find out the suspicious malignant nodules from benign cytology lesions before surgeries and reduce the false negative diagnoses of FNA and the missed diagnoses of thyroid cancer and improve the current management strategy of thyroid nodule FNA.

\section{Materials And Methods}




\section{Patients}

This retrospective study was authorized by the ethics committee of the Shanghai Tenth Hospital and complied with the Declaration of Helsinki. Informed consent of patients for this study were waived. From December 2016 to February 2018, 1232 consecutive patients with 1232 thyroid nodules were studied. The flow chart with specific inclusion and exclusion criteria is shown in Fig. 1. Eligible patients met the following criteria: (1) aged of 18 years or older; (2) FNA and BRAF V600E tests were performed;(3)CUS and SWE were examined before FNA; (4) surgical pathology results or follow-up more than one year with FNA results. The excluded criteria were as followed: (1) no surgical or FNA result; (2) FNA results with class I, III, IV, V, or VI subcategories; (3) BRAF600E mutation tests results were wild type; (4) incomplete information from the US and SWE images. Finally, 26 thyroid nodules from 26 patients with benign FNAB results and positive BRAFV600E gene results were included.

\section{US and 2D SWE examinations}

The same high-frequency linear transducer (SuperSonic imagine, Aix-en-Provence, France; 4-15 MHZ transducer) was applied in the CUS and SWE examinations from December 2016 to February 2018. Four physicians with over three years of experience on performing the following examinations. For CUS, the patients' necks should be fully exposed. At least six images were saved, including two grayscale images, two color Doppler images and images recording the size of the target nodule in the longitudinal and transverse planes. Before switching to SWE, a relaxed patient neck was essential for acquiring successful images. SWE was conducted by clearly visualizing and centering the nodule on a grayscale image. An appropriate sampling frame for elastography was chosen with two-thirds of which was occupied by the target nodule area, and the other one-third was occupied by normal thyroid tissues. The elastography scale set was selected uniformly at $100 \mathrm{KPa}$. During a breath hold, images were obtained after 3-5 seconds of stable operation with no pressure on the skin. Seven elastography images were obtained in the longitudinal plane. To quantitatively analyze the nodules' stiffness, the region of interest (ROI) should covered the nodules as much as possible. The optimal images were selected by two experienced radiologists who acquired the elastic values. The image selection criteria were as follows: (1) elastic graph assessed from a clear grayscale image; (2) clear outline of the target nodule on the elastic graph; (3) elasticity measurements that avoided calcification and cystic components; and (4) nodules of the same depth were surrounded by adequate thyroid tissue. Four parts of elastic values (E max, E min, E mean and E ratio) including the internal elastic values (EN max, EN min, EN mean), surrounding elastic values (ES max, ES min, ES mean) and the ratio of internal and surrounding values(E max ratio, E min ratio, E mean ratio) were obtained for the thyroid nodules.

\section{US FNAB and BRAF V600E test}

The appropriate path into the target nodule was guided by US. $21 \mathrm{G}$ fine needles were used for aspiration under continuous US guidance. Furthermore, cystic or calcified regions were avoided to improve the success rates of aspiration. Cytology samples were fixed immediately with $95 \%$ ethanol. Three samples were for cytology detection, and one for BRAF V600E testing. The selected tumor areas for BRAF V600E detection were stained with hematoxylin and eosin (HE) and evaluated under a microscope. A specific kit (QIAGEN QIAamp DNA FFPE Tissue) was used to extract DNA samples, and exon 15 of the V600E gene was detected by the Merinton SMA4000 spectrophotometer (Merinton Inc, Beijing, China).

\section{Statistical analysis}

Statistical analysis was performed by SPSS 20.0 software, and Fisher's exact test was used to evaluate categorical variables because of the small number of specimens $(\mathrm{n}<40)$. The differences between the mean values and standard deviations (SD) of continuous variables of the two groups were analyzed by independent-sample tests if the variables were normally distributed. The Mann-Whitney $U$ test was used if the continuous variables did not follow a normal distribution. P-value (two-sided) $<0.05$ indicated a statistically significant difference between two sets of data. The diagnostic efficiency including sensitivity, specificity, PPV, NPV, accuracy, +LR and -LR were evaluated by ROC curves generated by using MedCalc 19.0 software.

\section{Results}

\section{Patient characteristics}

A total of 1232 thyroid nodules from 1232 patients were received FNA and BRAF600E detection from December 2016 to February 2018 . Among them, 534 nodules were confirmed to be benign by cytology. After excluding the 498 nodules without BRAF V600E mutation, there were 36 nodules with benign cytology and BRAF V600E mutations. Among them, ten nodules were lost to follow-up. Two patients did not received surgery due to cardiac insufficiency according to the medical records, and 8 patients had been lost to follow-up. Eventually, 26 patients (26 males/ 0 females; mean age, $51.8 \mathrm{ys} / \mathrm{SD}, 11.6 \mathrm{ys}$; range from 31 to $72 \mathrm{ys}$ ) with 26 nodules were included in the retrospective study. The initial cytology results of these 26 patients were benign. Twenty-two thyroid nodules were removed by surgeries. Four patients had benign FNA results and were followed up for more than one year. The pathology results confirmed these nodules as nodular goiter in 2 ( $8 \%$ ) patients, papillary microcarcinoma in $18(84 \%)$ patients and papillary carcinoma in 2 (8\%) patients.

\section{CUS characteristics}


The basic information and CUS features were summarized in Table 1 and Table 2 . The CUS features showed that the undefined boundary ( $P=$ 0.010) and microcalcification $(P=0.018)$ were meaningful for differentiating between benign and malignant thyroid nodules, with areas under the ROC curve of 0.817 (95\% Cl: $0.617,0.940)$ and $0.792(95 \% \mathrm{Cl}: 0.588,0.925)$ respectively. The sensitivity, specificity, PPV, NPV, accuracy, +LR and LR were calculated and were $80.0 \%, 83.3 \%, 94.1 \%, 55.6 \%, 80.7 \%, 4.790$ and 0.240 for undefined boundary and $75.0 \%, 83.3 \%, 93.8 \% 50.0 \%, 76.9 \%$, 4.491 and 0.300 for microcalcification respectively. Of the 26 nodules, five (83\%) benign nodules had clear boundaries, and 16 ( $80 \%)$ of the 20 malignant nodules had undefined boundaries. Additionally, only one of the benign nodules had microcalcification and fifty nodules (75\%) had microcalcification in malignant nodules. The size, position, patient age, and sex of nodules were not significantly different between benign and malignant groups.

Table 1

Basic information of the benign and malignant nodules

\begin{tabular}{|c|c|c|c|}
\hline \multirow{2}{*}{$\begin{array}{l}\text { Characteristic } \\
\text { Age (mean) (y) }\end{array}$} & \multirow{2}{*}{$\begin{array}{l}\text { Benign nodules } \\
58.2 \pm 8.2\end{array}$} & \multicolumn{2}{|c|}{ Malignant nodules P-Value } \\
\hline & & $49.9 \pm 11.9$ & 0.127 \\
\hline \multicolumn{4}{|l|}{ Sex } \\
\hline Men & 0 & 0 & \\
\hline Women & 6 & 20 & 0.976 \\
\hline Maximum diameter (mm) & \multirow{3}{*}{$\begin{array}{l}7.0 \pm 3.1 \\
1\end{array}$} & \multicolumn{2}{|l|}{$6.9 \pm 3.7$} \\
\hline Undefined boundary & & & 0.010 \\
\hline Yes & & \multicolumn{2}{|l|}{16} \\
\hline No & 5 & \multicolumn{2}{|l|}{4} \\
\hline \multicolumn{3}{|l|}{ Irregular shape } & \multirow[t]{2}{*}{0.112} \\
\hline Yes & 3 & 17 & \\
\hline No & 3 & 3 & \\
\hline \multicolumn{2}{|l|}{$\mathrm{L} / \mathrm{T}$ ratio } & & 0.921 \\
\hline$<1$ & 5 & \multicolumn{2}{|l|}{17} \\
\hline$>1$ & 1 & \multicolumn{2}{|l|}{3} \\
\hline \multicolumn{2}{|l|}{ Halo sign } & & 0.585 \\
\hline Yes & 0 & \multicolumn{2}{|l|}{2} \\
\hline No & 6 & \multicolumn{2}{|l|}{18} \\
\hline \multicolumn{2}{|l|}{ Echogenicity } & & 0.723 \\
\hline Hyper & 0 & \multicolumn{2}{|l|}{1} \\
\hline Iso & 0 & \multicolumn{2}{|l|}{0} \\
\hline Нyро & 6 & \multicolumn{2}{|l|}{18} \\
\hline Markedly Hypo & 0 & \multicolumn{2}{|l|}{1} \\
\hline \multicolumn{2}{|l|}{ Microcalcification } & & 0.018 \\
\hline Yes & 1 & \multicolumn{2}{|l|}{15} \\
\hline No & 5 & \multicolumn{2}{|l|}{5} \\
\hline \multicolumn{2}{|l|}{ Blood flow } & & 0.168 \\
\hline Yes & 5 & \multicolumn{2}{|l|}{5} \\
\hline No & 7 & \multicolumn{2}{|l|}{9} \\
\hline \multicolumn{4}{|l|}{ Lymphatic metastasis } \\
\hline Yes & 0 & \multicolumn{2}{|l|}{0} \\
\hline No & 6 & \multicolumn{2}{|l|}{20} \\
\hline
\end{tabular}


Table 2

Predictive value of conventional CUS features in 26 thyroid nodules

\begin{tabular}{|c|c|c|c|c|c|c|c|c|c|c|c|}
\hline US features & $\begin{array}{l}\text { Benign } \\
(n=6)\end{array}$ & $\begin{array}{l}\text { Malignant } \\
(\mathrm{n}=20)\end{array}$ & $\begin{array}{l}\text { P- } \\
\text { value* }\end{array}$ & $+\mathrm{LR}$ & -LR & Sensitivity & Specificity & PPV & NPV & Accuracy & $\begin{array}{l}\text { AUC } \\
(95 \% \mathrm{Cl})\end{array}$ \\
\hline Boundary & 5 & 4 & 0.010 & 4.790 & 0.240 & $80.0 \%$ & $83.3 \%$ & $94.1 \%$ & $55.6 \%$ & $80.7 \%$ & 0.817 \\
\hline Defined & 1 & 16 & & & & $(16 / 20)$ & $(5 / 6)$ & $(16 / 17)$ & $(5 / 9)$ & $(21 / 26)$ & $(0.617,0.940)$ \\
\hline \multicolumn{12}{|l|}{ Undefined } \\
\hline \multirow{2}{*}{$\begin{array}{l}\text { Micro } \\
\text { calcification } \\
\text { Yes }\end{array}$} & 1 & 15 & 0.018 & 4.491 & 0.300 & $75.0 \%$ & $83.3 \%$ & $93.8 \%$ & $50.0 \%$ & $76.9 \%$ & 0.792 \\
\hline & 5 & 5 & & & & $(15 / 20)$ & $(5 / 6)$ & $(15 / 16)$ & $(5 / 10)$ & $(20 / 26)$ & $(0.588,0.925)$ \\
\hline No & & & & & & & & & & & \\
\hline
\end{tabular}

\section{SWE characteristics}

The elastic parameters including E max, E min and E mean of the thyroid nodules and surrounding tissues were obtained from the elastic graphs. There were no significant differences in $\mathrm{E}$ max, $\mathrm{E}$ min, $\mathrm{E}$ mean and $\mathrm{E}$ ratio parameters between the benign and malignant groups as shown in Table 3. Additionally, based on the cutoff values analyzed in ROC, EN max, EN min, EN mean, E max ratio, E min ratio and E mean ratio were divided into binary variable with the cutoff values of $25.8 \mathrm{KPa}, 13.5 \mathrm{KPa}, 21.5 \mathrm{KPa}, 1.49,1.20$ and 1.21 respectively. E max ratio with the cutoff value of 1.49 was meaningful for differentiating between benign and malignant thyroid nodules $(p=0.018)$ and showed the areas under the ROC curve of 0.792 (95\% Cl: 0.617, 0.940). The sensitivity, specificity, PPV, NPV, accuracy, +LR and -LR were calculated and were 75.0\%, 83.3\%, 93.8\%, $50.0 \%, 79.6 \%, 4.491$ and 0.300 . There were no differences between the benign and malignant groups in EN max, EN min, EN mean, EN min ratio and EN mean ratio (Table 4).

Table 3

The SWE characteristics of the thyroid nodules and surrounding tissues

\begin{tabular}{|c|c|c|c|}
\hline SWE parameter & Benign thyroid nodules (kPa) & Malignant thyroid nodules (kPa) & P-Value* \\
\hline \multicolumn{4}{|l|}{$E \max$} \\
\hline EN & $26.56 \pm 6.74$ & $35.59 \pm 16.71$ & 0.214 \\
\hline ES & $22.01 \pm 9.08$ & $18.69 \pm 12.23$ & 0.426 \\
\hline ER & $1.29 \pm 0.30$ & $1.91 \pm 0.76$ & 0.066 \\
\hline \multicolumn{4}{|l|}{ E min } \\
\hline EN & $14.63 \pm 6.54$ & $14.93 \pm 7.29$ & 0.928 \\
\hline ES & $12.23 \pm 5.64$ & $11.83 \pm 4.76$ & 0.863 \\
\hline ER & $1.44 \pm 1.07$ & $1.37 \pm 0.82$ & 0.853 \\
\hline \multicolumn{4}{|l|}{ E mean } \\
\hline EN & $20.65 \pm 4.82$ & $22.86 \pm 9.98$ & 0.608 \\
\hline ES & $16.95 \pm 5.35$ & $14.60 \pm 5.50$ & 0.366 \\
\hline ER & $1.26 \pm 0.27$ & $1.60 \pm 0.55$ & 0.165 \\
\hline \multicolumn{4}{|c|}{ EN: elastic values of the thyroid nodule. } \\
\hline \multicolumn{4}{|c|}{ ES: elastic values of the surrounding thyroid tissues. } \\
\hline \multicolumn{4}{|c|}{ ER: the elastic value ratio between benign and malignant nodules. } \\
\hline *Difference betw & n the two groups ("Benign" anc & Malignant"). & \\
\hline
\end{tabular}


Table 4

Predictive value of SWE parameters in 26 thyroid nodules

\begin{tabular}{|c|c|c|c|c|c|c|c|c|c|c|c|}
\hline $\begin{array}{l}\text { SWE } \\
\text { parameter }\end{array}$ & $\begin{array}{l}\text { Benign } \\
(n=6)\end{array}$ & $\begin{array}{l}\text { Malignant } \\
(n=20)\end{array}$ & $\begin{array}{l}\text { P- } \\
\text { value* }\end{array}$ & +LR & $-L R$ & Sensitivity & Specificity & PPV & NPV & Accuracy & $\begin{array}{l}\text { AUC } \\
(95 \% \mathrm{Cl})\end{array}$ \\
\hline$E \max$ & 3 & 6 & 0.332 & 1.400 & 0.600 & $70.0 \%$ & $50.0 \%$ & $82.4 \%$ & $33.3 \%$ & $65.4 \%$ & 0.600 \\
\hline$\leq 25.80$ & 3 & 14 & 0.529 & 1.124 & 0.750 & $(14 / 20)$ & $(3 / 6)$ & $(14 / 17)$ & $(3 / 9)$ & $(17 / 26)$ & $(0.391,0.785)$ \\
\hline$>25.80$ & 2 & 5 & 0.332 & 1.651 & 0.674 & $75.0 \%$ & $33.3 \%$ & $78.9 \%$ & $28.6 \%$ & $65.4 \%$ & 0.542 \\
\hline$E$ min & 4 & 15 & 0.018 & 4.491 & 0.300 & $(15 / 20)$ & $(2 / 6)$ & $(15 / 19)$ & $(2 / 7)$ & $(17 / 26)$ & $(0.337,0.737)$ \\
\hline$\leq 13.55$ & 4 & 9 & & & & $55.0 \%$ & $66.7 \%$ & $84.6 \%$ & $30.8 \%$ & $57.6 \%$ & 0.608 \\
\hline$>13.55$ & 2 & 11 & & & & $(11 / 20)$ & $(4 / 6)$ & $(11 / 13)$ & $(4 / 13)$ & $(15 / 26)$ & $(0.399,0.792)$ \\
\hline E mean & 5 & 5 & & & & $75.0 \%$ & $83.3 \%$ & $93.8 \%$ & $50.0 \%$ & $76.9 \%$ & 0.792 \\
\hline$\leq 21.50$ & & & & & & $(15 / 20)$ & $(5 / 6)$ & $(15 / 16)$ & $(5 / 10)$ & $(20 / 26)$ & $(0.617,0.940)$ \\
\hline \multicolumn{12}{|l|}{$>21.50$} \\
\hline \multicolumn{12}{|l|}{ E max ratio } \\
\hline \multicolumn{12}{|l|}{$\leq 1.49$} \\
\hline$>1.49$ & 1 & 15 & 0.248 & 1.801 & 0.599 & $60.0 \%$ & $66.7 \%$ & $85.7 \%$ & $33.3 \%$ & $61.5 \%$ & 0.633 \\
\hline E min ratio & 4 & 8 & 0.112 & 1.700 & 0.300 & $(12 / 20)$ & $(4 / 6)$ & $(12 / 14)$ & $(4 / 12)$ & $(16 / 26)$ & $(0.423,0.812)$ \\
\hline$\leq 1.20$ & 2 & 12 & & & & $85.0 \%$ & $50.0 \%$ & $85.0 \%$ & $50.0 \%$ & $76.9 \%$ & 0.675 \\
\hline$>1.20$ & 3 & 3 & & & & $(17 / 20)$ & $(3 / 6)$ & $(17 / 20)$ & $(3 / 6)$ & $(20 / 26)$ & $(0.465,0.844)$ \\
\hline $\begin{array}{l}\text { E mean } \\
\text { ratio }\end{array}$ & 3 & 17 & & & & & & & & & \\
\hline \multicolumn{12}{|l|}{$\leq 1.21$} \\
\hline$>1.21$ & & & & & & & & & & & \\
\hline
\end{tabular}

\section{Discussion}

FNA has become the predominant method for preoperative diagnosis of thyroid nodules with the risk of malignancy according to Thyroid Imaging Reporting and Data System (TI-RADS) classification. FNA were performed, and then the cytology results were graded according to Bethesda System for Reporting Thyroid Cytopathology. The cytology reporting system had good coherence in large groups of patients, with $89 \%-95 \%$ of samples being acceptable; $55 \%-74 \%$ of samples were benign, and $2 \%-5 \%$ were malignant[15]. However, the false negative rate for benign thyroid nodules in cytology is still as high as $5 \%[16]$. The risk of malignancy $(0-3 \%)$ also exists, even for cytology benign nodules (class II), especially if the nodule had suspicious malignant features. Similarly, twenty of 534 cytology benign nodules were pathologically confirmed malignancy in our study and the false negative rate accounted for $3.7 \%$. Under the guidance of the current FNA strategy, these malignant nodules with benign cytological results might be missed without further treatment[15].

The combined FNA and BRAF V600E tests were well known to effectively improve the diagnostic accuracy, especially for predicting the results of atypia or follicular lesion of undetermined significance (AUS/FLUS) cytology samples and had a high specificity[17]. The BRAF V600E test was proposed to refine the risk of malignancy, and surgical management would change based on the presence of positive results[18]. In a metaanalysis, the findings suggested that better risk stratification and treatment options were possible for MPTC with BRAF V600E mutations than those without BRAF V600E mutations[19]. For thyroid nodules found to be benign with FNA cytology, it was unpractical and did not meeting the ATA guideline to do BRAF V600E test. However, thirty-six nodules of 534 nodules with benign FNA results were confirmed as positive results of BRAF V600E in our data, and the application of the BRAF(V600E) test is expensive and not available in clinical[5]. How to find out the suspicious nodules in the cytological benign nodules and reduce the false negative rate of FNA before operation is an important problem. Our study retrospectively analyzed whether SWE and CUS features can be used to improve to find out suspicious nodules with benign cytology results and then combined BRAF V600E mutation results to reduce the number of preoperative missed diagnosis.

SWE, an available noninvasive method, has been widely used for qualitative and quantitative analysis. Throughout the years that SWE was in development, Carmela Asteria already reported that US elastography was promising for identifying potentially malignant thyroid nodules[14]. Many subsequent prospective and retrospective studies had interpreted the diagnostic efficacy of elastic assessments for benign and malignant 
thyroid nodules with both qualitative and quantitative modes and two-dimensional and three-dimensional techniques[20]. Elastography of ARFI also showed the special diagnostic superiority in thyroid nodules less than $10 \mathrm{~mm}$ [21]. To date, few research has assessed the diagnostic value of SWE in identifying thyroid nodules with benign cytology and positive BRAF V600E results. Based on our study, we concluded that SWE parameter with $\mathrm{E}$ max ratio > 1.49 was significant factor for malignancy in thyroid nodules with benign cytology. It was consistent with previous researches that the ratio of elastic parameters (VTI area ratio) can be used to predict the malignancy of thyroid and also consistent with our results[22]. However, there is no statistical difference $(p=0.214)$ in benign and malignant nodules although the elastic value with SWE max of malignant nodules is higher than that of benign nodules $(35.59 \pm 16.71 \mathrm{vs} 26.56 \pm 6.74)$ and the results was conflict with previous researches which confirmed that SWE max was an important predictor of benign and malignant nodules[23].

In our study, $22(85 \%)$ nodules had a maximum diameter less than $10 \mathrm{~mm}$, and the number of nodules with a maximum diameter less than $10 \mathrm{~mm}$ was not significant between benign and malignant nodules ( $83 \%$ vs $86 \%$ ). The part of the reason for the FNA misdiagnosis might be that several cells of the thyroid nodule cytology sample were unable to reflect the morphology of the nodule tissue and that of the adjacent to the surrounding tissues. Nodule size may also be one of the factors that account for the accuracy of FNA[24][25]. Additionally, the pathological results showed that 18 of 20 PTCs were MPTCs, which was considered an FNA omission due to the small diameter of the cancer. Although there were missing positive results with FNA, the thyroid nodules with suspicious US features were recommended for genetic tests since the mutation of BRAF V600E might be a prognostic factor of MPTC[26]. According to the ATA guidelines, nodules with class III or IV cytology results cannot be classified. Several studies had been reported that the malignancy of thyroid nodules with AUS/FLUS could be predicted by suspicious US features (irregular margins, taller-than-wide shape, marked hypo echogenicity or microcalcification), which increased the cancer risk to 60-90\%[27]. Moreover, the number of suspicious US features can predict the malignancy of thyroid nodules that had benign FNA results but were pathologically proven to be malignant[28]. In our research, suspicious US features with undefined boundary and microcalcification can be suggestive of malignancy, therefore BRAF V600E gene detection is necessary for these thyroid nodules with above malignant features, even if the cytological results were benign.

There were two patients with benign cytology and preoperative BRAF V600E mutations, but the histology results were benign. Both nodules in these two patients showed a solid component. one nodule had an undefined boundary, and the other nodule extended from the isthmus but had a clear boundary. There were two reasons for this situation in the analysis, one was that the FNA BRAF V600E test was false positive before surgery; the other was that the nodule gene was mutated, but the cellular tissue morphology had not changed significantly and cannot be diagnosed malignant by histology[29].

There were some limitations in our study. First, the sample of this retrospective study was relatively small and only 26 thyroid nodules were included. There are fewer cases to make it unclear that the $\mathrm{p}$ value of $E$ max ratio was 0.066 . Second, of the 10 patients who were lost to followup, 8 patients could not be contacted and 2 patients could not be operated because of failed cardiac function assessment. the loss of 10 thyroid nodules may influence the accuracy of the risk-stratification assessment. Third, the small diameters with $85 \%$ nodules that were less than 10 mm were important factors for the false negative results of FNA and SWE parameter although no significant differences of elastic diagnostic efficacy between nodule size in other research[21]. However, we need more cases and prospective studies to verify our results especially the performances of SWE in future studies.

\section{Conclusions}

Undefined boundary, microcalcification and $\mathrm{E}$ max ratio > 1.49 were risk factors for malignancy in thyroid nodules with benign cytology. When the FNA results were benign but the above three characteristics could be found in the thyroid nodules with BRAF V600E mutation, further clinical decisions should be carried out. The results of this study will be helpful to improve the current FNA strategy of thyroid nodules.

\section{List Of Abbreviations}

US: Ultrasound; FNA: fine-needle aspiration; SWE: shear wave elastography; CUS: conventional US; ROC: Receiver operating characteristic; MPTC: micro papillary thyroid carcinoma; PPV : positive predictive value; NPV: negative predictive value; FNA: fine-needle aspiration; ROI: region of interest; SD: standard deviations; TI-RADS: Thyroid Imaging Reporting and Data System; ATA: American Thyroid Association

\section{Declarations}

\section{Ethics approval and consent to participate}

This retrospective study was authorized by the ethics committee of the Shanghai Tenth Hospital (SHSY-IEC-4.1/20-15/01) and complied with the Declaration of Helsinki. Every patient who underwent the study signed the informed consent form.

\section{Consent for publication}


Not applicable.

Availability of data and materials

All data generated or analyzed during this study are included in this published article.

\section{Competing interests}

The authors declare that they have no competing interests.

\section{Funding}

This study was supported by National Natural Science Foundation of China (Grant No.81772849).

\section{Authors' contributions}

Yi-Feng Zhang and Ying Zhang designed this study. Ying Zhang and Feng Lu analyzed the data and wrote this manuscript. Ying Zhang, HanXiang Wang and Hui Shi were responsible for data gathering. Feng Lu and Le-Hang Guo completed FNAs of thyroid nodules. Xue-Chen Sun and Qing Wei were responsible for FNA cytology diagnosis in this study. All authors have read and approved the final manuscript.

\section{Acknowledgements}

Not applicable.

\section{Authors' information}

Ying Zhang and Feng Lu contributed equally to this work and should be considered co-first authors.

\section{References}

1. Smith-Bindman R, Lebda P, Feldstein VA, Sellami D, Goldstein RB, Brasic N, et al. Risk of thyroid cancer based on thyroid ultrasound imaging characteristics: results of a population-based study. JAMA Internal Medicine. 2013;173(19);1788-96.

2. Tessler FN, Middleton WD, Grant EG, Hoang JK, Berland LL, Teefey SA, et al. 2017 ACR Thyroid imaging, reporting and data system (TI-RADS): white paper of the ACR TI-RADS Committee. Journal of the American College of Radiology. 2017;14(5);587-595.

3. Danese D, Sciacchitano S, Farsetti A, Andreoli M, Pontecorvi A. 1998 Diagnostic accuracy of conventional versus sonography-guided fineneedle aspiration biopsy of thyroid nodules. Thyroid. 1998; 8(1);15-21.

4. Alexander EK. Approach to the patient with a cytologically indeterminate thyroid nodule. The Journal of clinical endocrinology and metabolism. 2008;93(11):4175-4182.

5. Haugen BR, Alexander EK, Bible KC, Doherty GM, Mandel SJ, Nikiforov YE, et al. 2015 American Thyroid Association Management Guidelines for Adult Patients with Thyroid Nodules and Differentiated Thyroid Cancer: The American Thyroid Association Guidelines Task Force on Thyroid Nodules and Differentiated Thyroid Cancer. Thyroid : official journal of the American Thyroid Association. 2016;26(1):1-133.

6. Xing M, Haugen BR, Schlumberger M. Progress in molecular-based management of differentiated thyroid cancer. Lancet (London, England). 2013;381(9871):1058-1069

7. Huang Y, Qu S, Zhu G, Wang F, Liu R, Shen X, et al. BRAF V600E Mutation-Assisted Risk Stratification of Solitary Intrathyroidal Papillary Thyroid Cancer for Precision Treatment. Journal of the National Cancer Institute. 2018;110(4):362-370.

8. Cohen Y, Rosenbaum E, Clark DP, Zeiger MA, Umbricht CB, Tufano RP, et al. Mutational analysis of BRAF in fine needle aspiration biopsies of the thyroid: a potential application for the preoperative assessment of thyroid nodules. Clinical cancer research : an official journal of the American Association for Cancer Research. 2004;10(8):2761-2765.

9. Zatelli MC, Trasforini G, Leoni S, Frigato G, Buratto M, Tagliati F, et al. BRAF V600E mutation analysis increases diagnostic accuracy for papillary thyroid carcinoma in fine-needle aspiration biopsies. European journal of endocrinology. 2009;161(3):467-473.

10. Suh YJ, Choi YJ. Strategy to reduce unnecessary surgeries in thyroid nodules with cytology of Bethesda category III (AUS/FLUS): a retrospective analysis of 667 patients diagnosed by surgery. Endocrine. 2020.

11. Asteria C, Giovanardi A, Pizzocaro A, Cozzaglio L, Morabito A, Somalvico F, et al. US-elastography in the differential diagnosis of benign and malignant thyroid nodules. Thyroid. 2008;18(5):523-31

12. Liu B, Liang J, Zheng Y, Xie X, Huang G, Zhou L, et al. Two-dimensional shear wave elastography as promising diagnostic tool for predicting malignant thyroid nodules: a prospective single-centre experience. European radiology. 2015;25(3):624-634.

13. Chen L, Shi YX, Liu YC, Zhan J, Diao XH, Chen Y, et al. The values of shear wave elastography in avoiding repeat fine-needle aspiration for thyroid nodules with nondiagnostic and undetermined cytology. Clinical endocrinology. 2019;91(1):201-8.

Page $8 / 13$ 
14. Samir AE, Dhyani M, Anvari A, Prescott J, Halpern EF, Faquin WC, et al. Shear-Wave Elastography for the Preoperative Risk Stratification of Follicular-patterned Lesions of the Thyroid: Diagnostic Accuracy and Optimal Measurement Plane. Radiology. 2015;277(2):565-573.

15. Cibas ES, Ali SZ. The Bethesda System for Reporting Thyroid Cytopathology. Thyroid : official journal of the American Thyroid Association. 2009;19(11):1159-1165.

16. Ylagan LR, Farkas T, Dehner LP. Fine needle aspiration of the thyroid: a cytohistologic correlation and study of discrepant cases. Thyroid : official journal of the American Thyroid Association. 2004;14(1):35-41.

17. Adeniran AJ, Hui P, Chhieng DC, Prasad ML, Schofield K, Theoharis C. BRAF mutation testing of thyroid fine-needle aspiration specimens enhances the predictability of malignancy in thyroid follicular lesions of undetermined significance. Acta cytologica. 2011;55(6):570-575.

18. Nikiforov YE, Ohori NP, Hodak SP, Carty SE, LeBeau SO, Ferris RL, et al. Impact of mutational testing on the diagnosis and management of patients with cytologically indeterminate thyroid nodules: a prospective analysis of 1056 FNA samples. The Journal of clinical endocrinology and metabolism. 2011;96(11):3390-3397. 298

19. Chen Y, Sadow PM, Suh H, Lee KE, Choi JY, Suh YJ, et al. BRAF(V600E) Is Correlated with Recurrence of Papillary Thyroid Microcarcinoma: A Systematic Review, Multi-Institutional Primary Data Analysis, and Meta-Analysis. Thyroid : official journal of the American Thyroid Association. 2016;26(2):248-255.

20. Zhao CK, Chen SG, Alizad A, He YP, Wang Q, Wang D, et al. Three-Dimensional Shear Wave Elastography for Differentiating Benign From Malignant Thyroid Nodules. Journal of ultrasound in medicine: official journal of the American Institute of Ultrasound in Medicine. 2018;37(7):1777-1788.

21. Zhang YF, Xu HX, Xu JM, Liu C, Guo LH, Liu LN, et al. Acoustic Radiation Force Impulse Elastography in the Diagnosis of Thyroid Nodules Useful or Not Useful. Ultrasound in Medicine and Biology. 2015;41(10):2581-2593.

22. Xu JM, Xu HX, Li XL, Bo XW, Xu XH, Zhang YF, et al. A Risk Model for Predicting Central Lymph Node Metastasis of Papillary Thyroid Microcarcinoma Including Conventional Ultrasound and Acoustic Radiation Force Impulse Elastography. Medicine. 2016;95(3): e2558.

23. He YP, Xu HX, Li XL, Li DD, Bo XW, Zhao CK, Liu BJ, et al. Comparison of Virtual Touch Tissue Imaging \& Quantification (VTIQ) and Toshiba shear wave elastography (T-SWE) in diagnosis of thyroid nodules: Initial experience. Clinical hemorheology microcirculation. 2017;66(1):1526.

24. Moon HJ, Son E, Kim EK, Yoon JH, Kwak JY. The diagnostic values of ultrasound and ultrasound-guided fine needle aspiration in subcentimeter-sized thyroid nodules. Annals of surgical oncology. 2012;19(1):52-59.

25. Giles WH, Maclellan RA, Gawande AA, Ruan DT, Alexander EK, Moore FD, et al. False negative cytology in large thyroid nodules. Annals of surgical oncology. 2015;22(1):152-157.

26. Kwak JY, Kim EK, Chung WY, Moon HJ, Kim MJ, Choi JR. Association of BRAFV600E mutation with poor clinical prognostic factors and US features in Korean patients with papillary thyroid microcarcinoma. Radiology. 2009;253(3):854-860.

27. Rosario PW. Thyroid nodules with atypia or follicular lesions of undetermined significance (Bethesda Category III): importance of ultrasonography and cytological subcategory. Thyroid : official journal of the American Thyroid Association. 2014;24(7):1115-1120. 324.

28. Chen X, Zhou Q, Wang F, Zhang F, Du H, Zhang Q, et al. Value of V600E in High-Risk Thyroid Nodules with Benign Cytology Results. AJNR American journal of neuroradiology. 2018;39(12):2360-2365.

29. Zhao CK, Zheng JY, Sun LP, Xu RY, Wei Q, Xu HX. BRAF mutation analysis in fine-needle aspiration cytology specimens for diagnosis of thyroid nodules: The influence of false-positive and false-negative results. Cancer medicine. 2019;8(12):5577-5589.

\section{Figures}


Fig 1

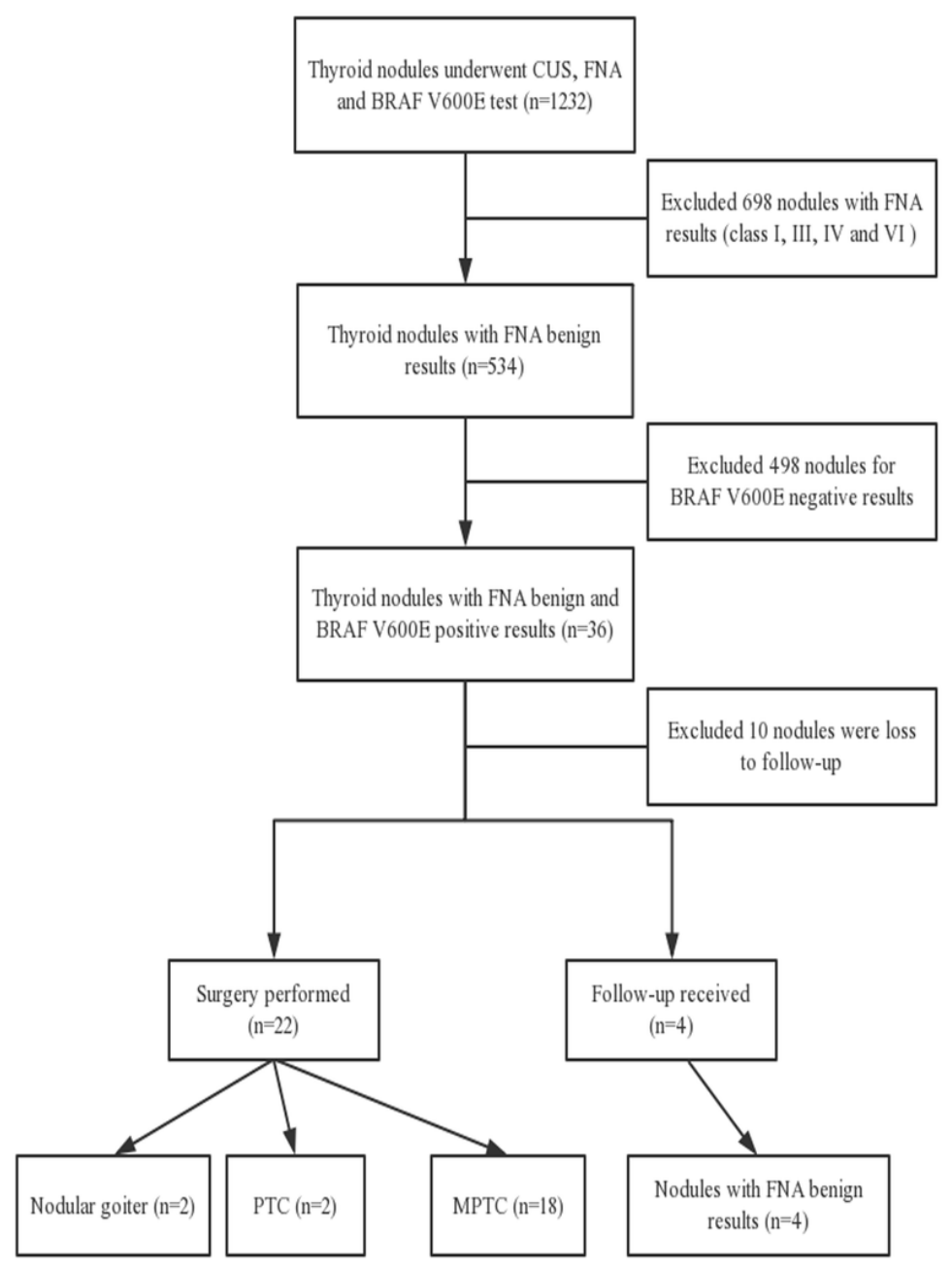

Figure 1

Process for including nodules and the histopathology examination results. 


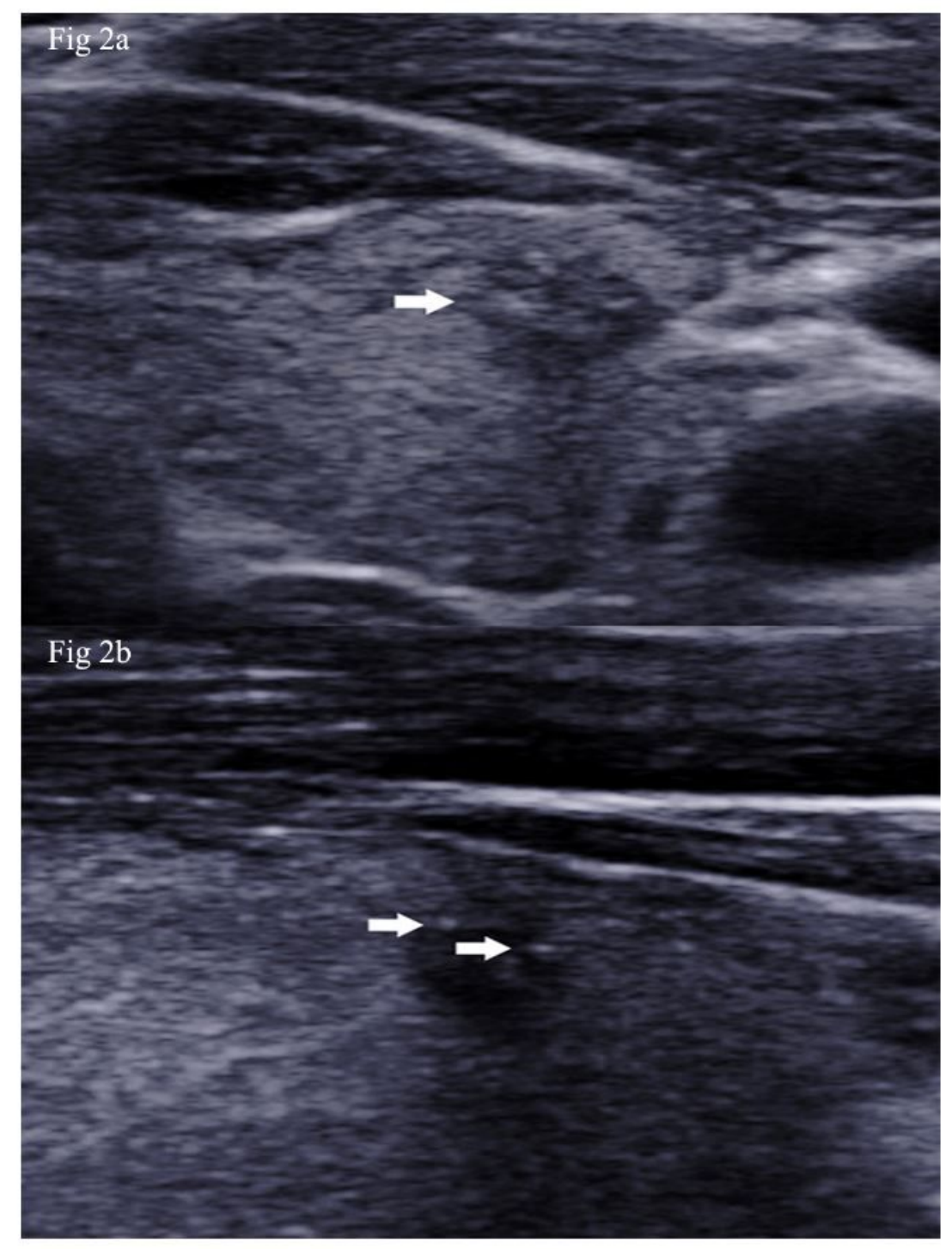

Figure 2

Images of a 36-year-old woman with PTC and negative FNA results. (a) CUS showed unclear boundaries in the longitudinal planes. (b) CUS showed the micro calcification in the transverse planes. 


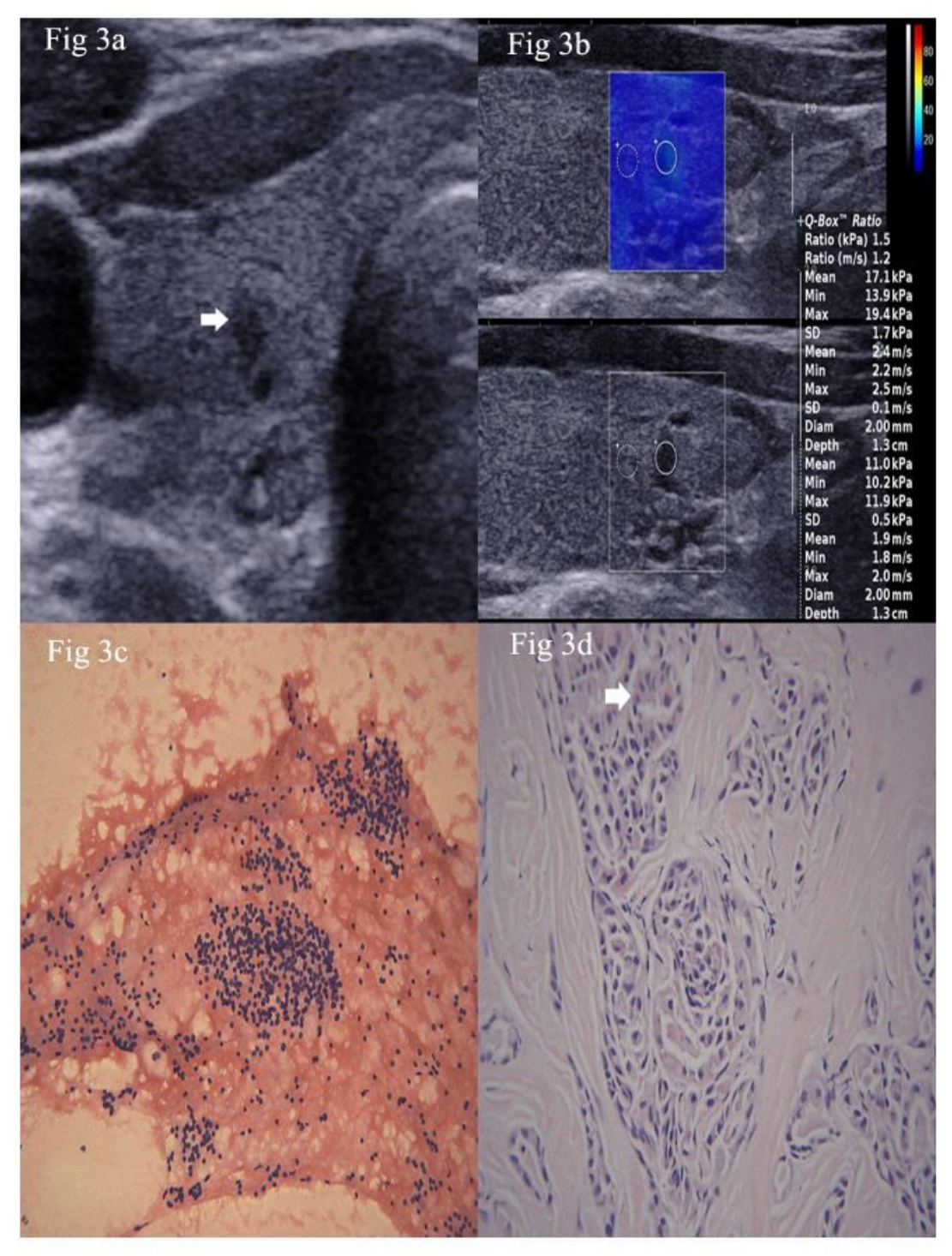

\section{Figure 3}

Images of a 59-year-old woman with PTC and negative FNA results. (a) CUS showed irregular shape and L/T ratio<1 in the transverse plane. (b) The hardness of the nodule was showed on elasticity diagram and the comparison of SWE parameters between the thyroid nodules and surrounding normal tissue was equally matched. E max ratio showed the value $>1.49$. (c) The initial cytology diagnosis was benign by US FNA (HE stain, magnification 4X10). (d) The final pathological result of this nodule was PTC (HE stain, magnification 10X10). 
Fig $4 \mathrm{a}$

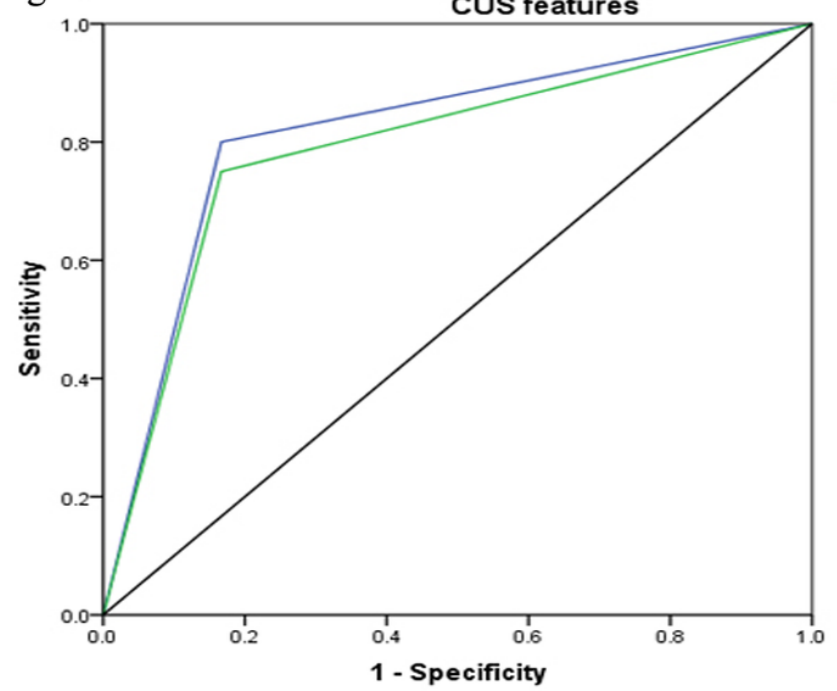

- Undefined boundary

Fig $4 \mathrm{~b}$

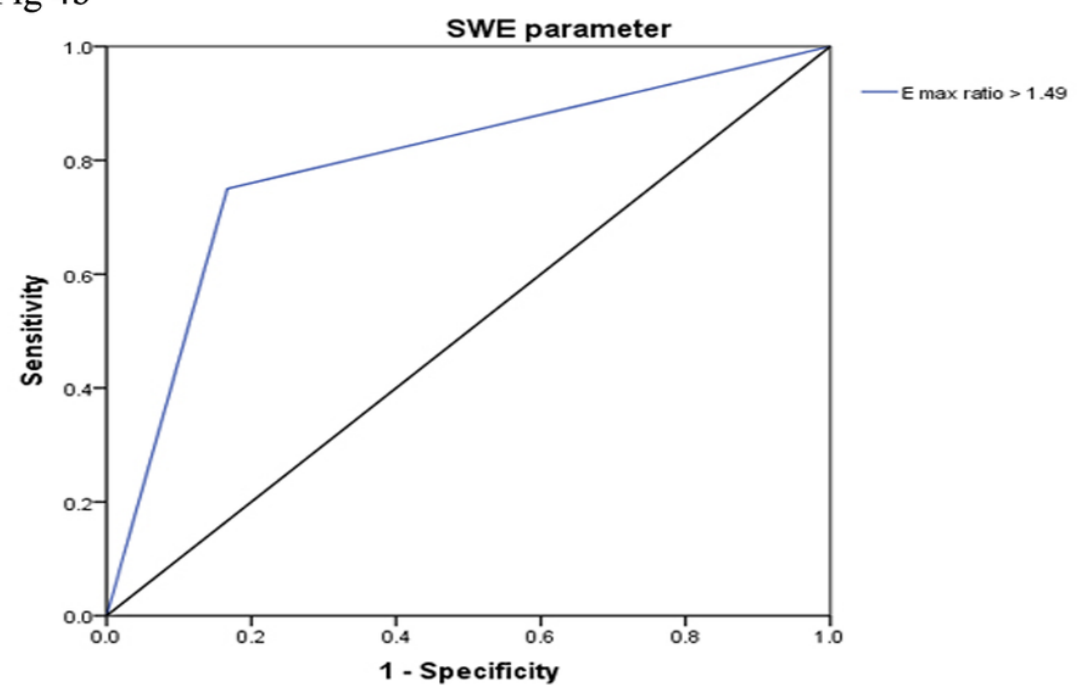

Figure 4

ROC curves showing the performance of US features with the undefined boundary and microcalcification and SWE parameter with E max ratio > 1.49 in evaluating malignant thyroid nodules with areas under the ROC curve of 0.817 ( $95 \% \mathrm{Cl}: 0.617,0.940 ; \mathrm{P}=0.010), 0.792$ ( $95 \% \mathrm{Cl}: 0.588$, $0.925 ; \mathrm{P}=0.018)$ and 0.792 (95\% Cl: $0.617,0.940 ; \mathrm{P}=0.018)$ respectively. 